\title{
云南纳帕海岩溶湿地 生态环境变化及驱动机制*
}

\section{田 昆 1,2 陆 梅 2 常凤来 2 莫剑锋 $^{2}$ 黎良才 $^{2}$ 杨永兴 $^{3}$ \\ (1:中国科学院东北地理与农业生态研究所, 长春 130012 ; \\ 2:西南林学院环境科学与工程系, 昆明 $650224 ; 3$ :同济大学环境科学与工程学院, 上海 200092)}

\begin{abstract}
提 要 利用原状土就地取样野外定位研究方法, 对云南西北高原的纳帕海岩溶湿地生态环境 状况进行的 2 年定位研究表明, 纳帕海湿地生态环境破坏严重, 表现为湿地面积不断缩小, 沼泽类型 改变, 沼泽旱化、沙化, 中旱生植物侵入, 沼泽发生逆向生态演替, 生物多样性减少, 土壤养分衰减退 化, 土壤酶活性降低, 水质变劣. 分析了引起纳帕海湿地环境变化的自然因素和人为因素, 表明人为 活动干扰是引起其湿地生态环境退化的主要原因.
\end{abstract}

关键词 纳帕海 人为干扰 岩溶湿地 生态退化 驱动机制

分类号 $\mathrm{S} 156.8$

纳帕海是横断山脉石灰岩上发育形成的喀斯特型低纬度高海拔季节性高原沼泽湿地, 有 着若尔盖高原湿地和我国北方湿地所不具备的特点, 为我国湿地的独特类型. 但国内缺乏对 这一湿地的研究 ${ }^{[1]}$. 由于纳帕海湿地位于生态脆弱的横断山石灰岩地区, 地处长江上游, 有着 特殊的生态作用,一方面调节着冰雪融水、地表径流和河流水量, 控制着土壤侵蚀, 对长江下游 水位和水量均衡有着重要作用, 也调节着局地气候, 为动植物群落提供了复杂而完备的特殊生 境, 孕育了丰富的生物多样性; 并由于其兼有水体和陆地双重特征,为许多珍稀濒危物种提供 了栖息繁衍地, 同时也由于其特殊的多样性和天然牧场的重要地位, 为当地人民的生存提供了 丰富的资源. 另一方面, 这些湿地之间没有水道相通, 因而造就了丰富的生物特有现象，从而 也决定了其生态系统的脆弱性和不稳定性, 具有了特殊的生态意义和科研价值. 进行纳帕海 湿地生态环境退化研究, 了解湿地退化过程与规律, 剖析湿地生态环境退化特征与机制, 可为 湿地保护与退化湿地的恢复提供科学决策依据.

\section{1 研究区域及研究方法}

\section{1 纳帕海湿地生态环境特征}

纳帕海湿地地处金沙江流域,位于横断山脉中段云南省西北部 $\left(99^{\circ} 37^{\prime}-99^{\circ} 43^{\prime} \mathrm{E}, 27^{\circ} 49^{\prime}-\right.$ $\left.27^{\circ} 55^{\prime} \mathrm{N}\right)$, 海拔 $3260 \mathrm{~m}$, 属云南省海拔最高和纬度最北的高原湖泊湿地之一，也是沼泽化较为 严重和退化较为典型的湿地. 纳帕海四周山岭环绕, 从湖盆中心至湖岸边生长着大量的水生 和陆生植被, 湖滨分布有较大面积的沼泽草甸, 周围山上生长着硬叶常绿阔叶林和云冷杉针叶

* 湖北省涝渍灾害与湿地农业重点实验室开放科研基金 (HNKFJ2002A04) ,云南省自然科学基金 (2001C0044M)联合资助. 2003-06-10 收稿 2003-09-10 收修改稿. 田昆, 男, 1957 年生, 博士, 副教授. 
林以及灌丛. 湖盆发育在石灰岩母质的中甸高原上, 受喀斯特作用的强烈影响, 纳帕海湖盆底 部被蚀穿形成落水洞, 湖水在地下汇集后从北部穿过小背斜出露形成支流汇入金沙江. 水量 补给主要依靠降雨、地表径流、冰雪融水和湖两侧沿断裂带上涌的泉水. 受西南季风影响,6月 初形成大量降水, 但由于石灰岩漏水, 8月后湖水退落, 10 月前后由于秋季季风退缩再次产生 降雨, 湖水再次上涨并于 11 月后退落. 湖水退落后湖面大幅度缩小, 湖底暴露成为大片浅水 沼泽和沼泽草甸, 当地居民随即开发利用, 或圼为农田或放牧. 这一趋势虽在纳帕海湿地成为 自然保护区后得到遏制, 但放牧现象仍十分严重尤其是放养破坏性较大的家猪. 受自然和人 为因素的双重影响, 加之近几年来旅游开发和无序旅游的影响,生态环境发生了很大改变, 沼 泽草甸沙化, 土壤养分衰减退化, 空间上呈现出不同程度的生态退化现象.

\section{2 研究方法}

以空间代时间的方法, 选择常年积水的原生沼泽作为参照, 涨水时淹没, 退水时过湿的 浅水沼泽草甸, 完全排干的人为干扰较大的草甸和开垦利用的耕地四种湿地类型, 以及湖周 山坡上的灌丛和林地类型, 应用野外条件下定位研究的原状土就地取样技术 ${ }^{[2,3]}$, 研究不同退 化湿地类型上的土壤营养变化情况及其酶活性的响应, 并探讨森林植被对纳帕海湿地的影响, 通过野外实地调查研究湿地环境变化状况. 室内分析参照中国分析标准方法 ${ }^{[4]}$ 、中国科学院 南京土壤研究所《土壤性质理化分析》[5]和关松荫编著的《土壤酶及其研究法》[ ${ }^{6}$, 进行土壤有 机质 (重铬酸钾法)、全氮 (开氏法)、速效磷 (碳酸氢钠法、盐酸-氟化铵法)、速效钾 (火焰光度计 法)、铵态氮 (氯化钾浸提一蒸馏法)、硝态氮 (还原蒸馏法) 及土壤脲酶 (青定酚比色法) 和过氧化 氢酶 (高锰酸钾滴定法)、多酚氧化酶 (邻苯三酚比色法) 和蛋白酶 (狮三铜比色法) 活性的测 定, 并对分析数据进行统计分析.

\section{2 纳帕海湿地退化现状}

\section{1 湿地面积减少、沼泽旱化沙化严重}

近 20 年来, 纳帕海湖水面积和沼泽、草甸面积不断减少, 湿地生态系统变劣, 生境丧失十 分严重. 1981 年中国科学院考察队对横断山滇西北地区考察时, 报道纳帕海湖面积水面积 $60000 \mathrm{hm}^{2}$, 沼泽面积 $28200 \mathrm{hm}^{2[7]}$,2001 年作者对纳帕海自然保护区进行科学考察时发现沼泽 面积仅有 $2400 \mathrm{hm}^{2}$, 雨季时也仅 $3125 \mathrm{hm}^{2}$; 面积减少了近 10 倍 ${ }^{1}$. 在一年的大部分时间里，纳 帕海沼泽湿地都处于排水疏干状况下, 此时淹水面积仅 $500 \mathrm{hm}^{2}$ 左右, 湖中心水深由 4-5 $\mathrm{m}$ 降 至 $20 \mathrm{~cm}$, 水位下降了 20-25 倍, 有的低洼地沼泽水深不足 $10 \mathrm{~cm}$, 多数仅呈过湿状态, 这种排 水疏干的结果使纳帕海湿地被分割成许多部分而导致沼泽破碎化、旱化十分严重, 加之当地居 民放养的家猪拱翻表层草甸层找食食物，这种破坏远大于牲畜践踏对沼泽土草根层的机械捣 碎破坏, 不仅增加了土壤通气性, 加速了沼泽土有机质的分解, 加剧了矿化作用, 使其养分含量 下降, 土壤粘粒丧失, 分解度增大, 更为严重的是致使草根层裸露死亡, 整个表层破坏殆尽, 下 覆沙层出露而严重沙化, 加速了滇西北高原湖泊湿地的衰亡过程.

\section{2 沼泽退化演替}

纳帕海沼泽湿地原以杉叶藻 (Hippuris vulgaris) 群丛、刘氏荸荠-北水苦卖(Veronica

(1) 西南林学院. 云南碧塔海自然保护区综合科学考察报告, 2002 
anagoallis-aquatica) 群丛、华扁穗草-无翅苔草 (Blysmus sinocompressus-Carex pleistogyna) 群 丛和小黑三棱 (Sparganium simplex) 等为主 ${ }^{[8,9]}$, 并由于微地形引起的水热状况的微小变化, 使 小环境的沼生植物截然不同, 湿生植物种属丰富, 从而形成复杂多样的 8 种沼泽体 ${ }^{[7]}$ (图 1 ).

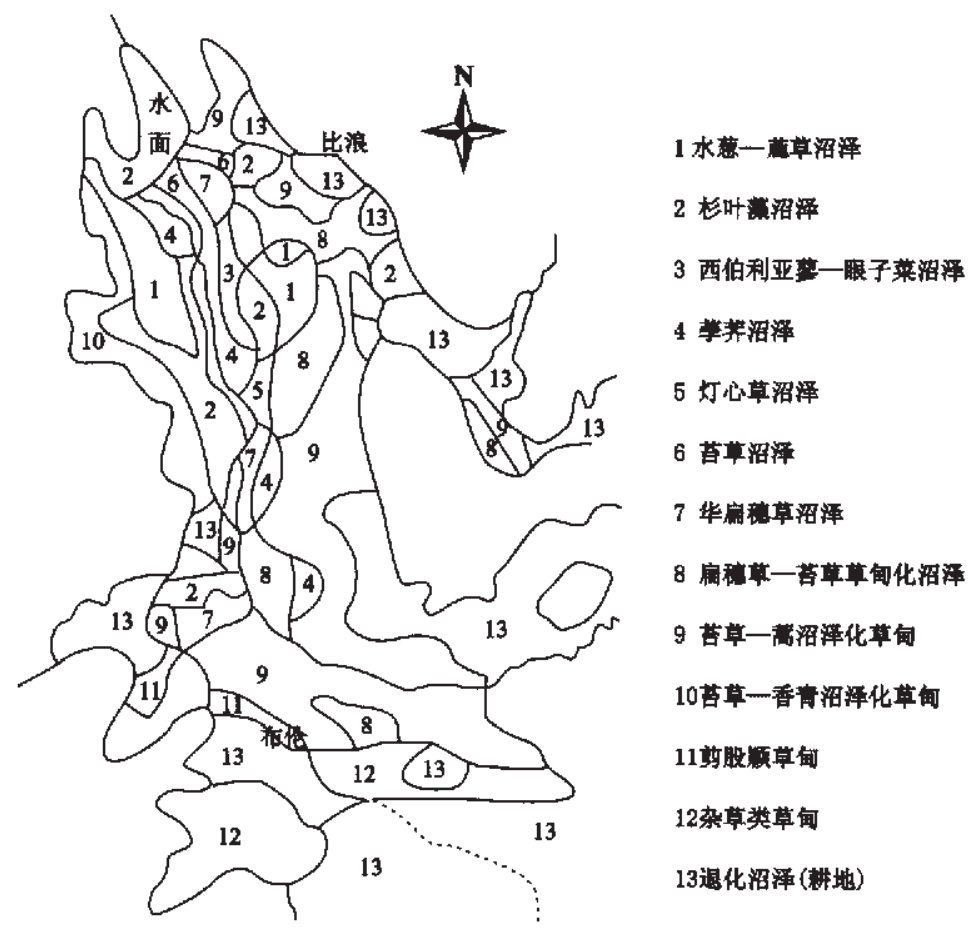

图 120 年前的纳帕海沼泽植被类型分布 ${ }^{[1]}$

Fig.1 Hydrophyte types before two decades in Napahai wetland ${ }^{[1]}$

由于人类活动的干预，纳帕海几乎被完全排干, 湖生种类所剩无几 ${ }^{[9]}$. 目前, 杉叶藻群落与 小黑三棱群落除在西北角和积水低洼处尚有分布外, 原有的沼泽植物包括伴生的蔍草 (Scirpus triagulatus var. sanquineus)、芠笋 (Zizania caduciflora)、水蓼 (Polygonum hydropiper)、菹草 (Potamogeton crispus)、蓠齿眼子菜 (Potamogeton maackianus)、水毛莨 (Batrachium bungei) 等 数量明显减少, 面积大幅度缩小, 分布范围急剧萎缩, 而需积水较浅的华扁穗草-无翅苔草沼 泽、浅水湿地植物如苦菜 (Nymphoides peltatum)、鸭子草 (Potamogeton tepperi)、丝草 (P. pusillus)、田字萍 (Marsilea quadrifolia)、狐尾藻 (Myriophyllum spicatum)、紫萍 (Spirodela polyrrhiza)、黑藻 (Hydrilla verticillata) 等则明显增多. 另外，锡金报春 (Primula sikkimensis)、抽 葶驴蹄草 (Caltha scaposa)、沿沟草 (Catabrosa aquatica)、疏花早熟禾 (Poa chalarantha)、发草 (Deschampsia caespitosa)、锡金柳叶菜 (Epilobium sikkimense)、矮地榆 (Sanguisorba filiformis)、粗齿堇菜(Viola urophylla)、走茎灯心草(Juncus amplifolius)、线叶嵩草 (Kobresia capillifolia)、短腺小米草 (Euphrasia regelii)、矮泽芹 (Chamaesium paradoxum)、斑唇马先蒿 (pedicularis longiflora var. tubiformis)、草血竭 (Polygonum paleaceum)、川滇毛茛 (Ranunculus potaninii) 等中生-旱生植物出现或显著增多 ${ }^{[10]}$, 最为显著的是出现了大狼毒 (Euphorbia jolkinii) 等沼泽退化的标志植物. 致使纳帕海湿地向沼泽一沼泽化草甸一草甸逆向生态方向演替. 此 
外, 纳帕海沼泽干涸部分或被开垦成为耕地或用于放牧, 不仅沼泽类型发生改变而且沼泽湿地 植被严重退化, 导致纳帕海沼泽逆向生态演替, 其过度放牧的逆向生态演替模式为沼泽一沼泽 化草甸一草甸一沙漠化地一荒漠, 如进一步破坏地表植被, 对沼泽开星以种植农作物则沼泽逆 向生态演替模式为沼泽一沼泽化草甸一草甸一耕地.

\section{3 重要水禽种群数量减少或消失}

云南西北部高原湿地为动植物群落提供了复杂而完备的特殊生境, 孕育了丰富的生物多 样性; 并由于其兼有水体和陆地双重特征, 为许多珍稀濒危物种提供了栖息繁衍地. 据中国科 学院昆明动物所及西南林学院研究, 纳帕海湿地分布有鸟类 41 种, 其中有不少属国家 I、II 级 重点保护动物，如黑颈鹤(Grus nigricollis)、黑鹳 (Ciconia nigra)、白马鸡 (Crossoptilon crossoptilon)、白琵鹭 (Platalea leucorodia)、赤麻鸭 (Tadoma ferruginea)、丹顶鹤 (Grus japonensis)、赤 颈鹤 (G. antigone)、大天鹅 (Cygnus cygnus) 以及省级保护水禽如灰赝 (Anser anser)、斑头雁 (A. indicus) 等. 由于环境胁迫, 湿地生态环境恶化, 食物来源减少, 水禽活动范围缩小, 许多珍 稀种种群数量或减少或消失. 这些重要水禽中, 丹顶鹤属国家 I 级保护种, 20 世纪 60 年代以前 数量较多, 王紫江 1980 年冬仅见 8-9 只, 1981 年仅见 5 只 ${ }^{[11]}$ 现已不见踪迹. 同属 I 级保护种 的赤颈鹤 1986 曾有捕获 现已绝迹 ${ }^{[12]}$. 奚志农 1992 年观察到国家 II 级保护种大天鹅 2 只 ${ }^{[13]}$, 现已看不到踪迹. 黑颈鹤属国家 I 级保护, 为世界上唯一生活在高原的鹤类,杨岗 1984 年 12 月观察到 149 只 ${ }^{[14]}$,魏天昊 1991 年 12 月仅见 70 只 ${ }^{[15]}$ 韩联宪 1994 年报道纳帕海越冬的数量 在 50-84 只之间 ${ }^{[7]}$, 黑颈鹤主要以黄蚬、小鱼、植物根茎为食, 尤以黄蚬最为重要, 而黄蚬在纳

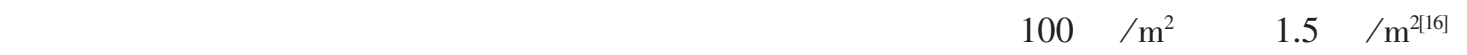
沼泽草甸中有活体 47.5 个 $/ \mathrm{m}^{2}$, 死体 24 个 $/ \mathrm{m}^{2}$, 退化草甸仅有活体 2 个 $/ \mathrm{m}^{2}$, 死体 28 个 $/ \mathrm{m}^{2}$, 开 垦为农耕地的沼泽已无黄蚬. 纳帕海建立保护区后, 虽制止了猎杀, 保护了种群个体, 但人为 活动和自然因素的双重胁迫引致的食物减少, 使这些重要水禽中许多珍稀种种群数量减少或 消失.

\section{4 土壤养分衰减退化}

排水疏干沼泽湿地, 导致沼泽土壤泥炭化、潜育化过程减弱或终止, 无论是用于放牧的草 甸, 还是排干垦殖为耕地, 均使表层处于较干燥的氧化环境下而利于有机质矿化, 导致土壤 全氮及有机质大幅度下降. 垂直分异上, 表层土有机质含量高达 $25 \%$,下层土仅 $1.24 \%$, 相差 20 倍; 水平分异上,有机质含量随沼泽化过程减弱而降低，即从原生沼泽的平均 $23.59 \%$ 逐渐 向沼泽草甸、退化草甸以及退化湿地一耕地下降, 下降的有机质含量分别为 $4.9 \% 、 4.6 \%$ 、 2.4\% ,下降幅度达 4.5-20 倍, 表明了有机质由沼泽条件下的积累过程到通气性增加的草甸 和耕地的分解过程. 全氮含量的总体变化呈现出与有机质相同的下降趋势. 空间垂直分异 上纳帕海湿地表层土壤全氮含量为 $0.45 \%$, 而下层土壤仅为 $0.043 \%-0.156 \%$,相差 3-10 倍; 水平分异上则从经常淹水的原生沼泽的全氮平均含量 $0.36 \%$, 逐渐向沼泽草甸、退化草甸、 耕地下降,下降的全氮含量分别为 $0.17 \% 、 0.16 \% 、 0.09 \%$,下降幅度达 2-4 倍(图 2). 与原生 沼泽相比较, 沼泽草甸和草甸的下降幅度最大, 有机质和全氮分别下降了 10 倍和 4 倍; 耕地 土壤有机质和全氮含量分别下降了 5 倍和 2 倍, 耕地的有机质和全氮下降幅度较退化草甸 小, 一方面可能与大量施用有机肥, 补充有机质有关, 另一方面与周围山上林地和灌丛土壤养 分随径流汇集补给有着密切关系, 耕地表层有机质和全氮含量均高于下层即为佐证. 


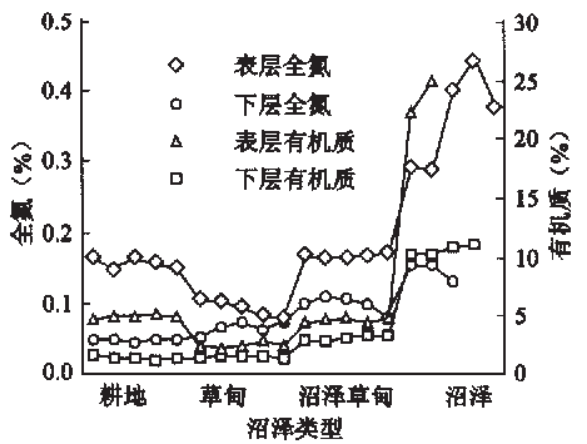

图 2 人为干扰下土壤有机质与全氮特征

Fig.2 Organic matter and total $\mathrm{N}$ under human disturbances

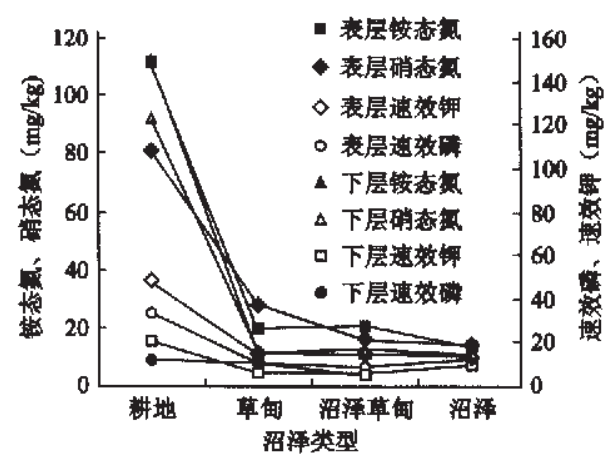

图 3 人为干扰下的速效养分特征

Fig.3 Available nutrients under human disturbances

原生沼泽土壤的铵态氮和硝态氮均较沼泽草甸和草甸土壤含量低, 并随通气性增加, 两 种形态的氮含量增加 (图 3). 在土壤过湿条件下, 沼泽草甸与原生沼泽相比较, 土壤铵态氮和 硝态氮含量变化不大,但草甸和耕地, 尤其是耕地土壤铵态氮和硝态氮含量呈现大幅度递增. 速效养分的速效钾随人为活动干扰的影响而降低, 速效磷则先下降并随人为活动影响加剧 而上升; 退化草甸下层的速效养分则下降; 沼泽草甸及退化草甸土壤与沼泽土壤相似, 空间垂 直分异上从上到下速效钾含量都偏低, 人为干扰较强的耕地土壤速效磷及速效钾含量均较高 (图 3 ).

\section{5 土壤酶活性的变化响应}

有机物质和有机残体的最初转化和转变为腐殖质, 是在酶的作用下进行的, 这两个最重 要的土壤生物化学过程连同腐殖质的进一步酶催化转化, 决定了土壤的演化进程和使土壤 保持稳衡的状态 ${ }^{[17]}$. 纳帕海沼泽土壤有机物质的积累转化及分解与土壤酶有着密切关系, 沼 泽类型的改变及其土壤的变化状况必然会由土壤酶活性表现出来, 且与土壤有机质等土壤 肥力因子之间存在相关关系 ${ }^{[18]}$.

研究表明, 不同沼泽类型的土壤酶活性存在差异, 在垂直方向上土壤酶活性也呈现出表 层大于下层的趋势, 存在着与土壤有机质等其它肥力因子相同的垂直空间规律和显著的正 相关关系. 土壤腿酶和过氧化氢酶活性与土壤全氮、有机质的变化趋势相同，从原生沼泽一 沼泽草甸一耕地-草甸逐渐降低, 这是因为土壤有机质和累积在其中的氮决定了酶进入土壤 中的数量, 是土壤酶生命活动的产物, 随着土壤有机质和土壤氮营养从原生沼泽改变为沼泽 草甸、草甸和耕地的衰减退化, 酶的生命活动物质减少, 活性必然降低. 多酚氧化酶和蛋白酶 活性的变化趋势则与此相反, 特别是多酚氧化酶与有机质、全氮呈显著负相关, 相关系数分 别为 $r^{2}=-0.9390 、 r^{2}=-0.8571 、 r^{2}=-0.8397$ 和 $r^{2}=-0.8397$. 蛋白酶是催化有机态氮分解为无机 态氮的酶类, 蛋白酶活性高, 有机氮化物的转化率就高, 土壤可利用态氮也就丰富, 表明随沼 泽湿地通气性增加, 有机质从积累转为分解, 矿化加强, 进行分解的多酚氧化酶、蛋白酶活性 自然随之增加, 较好地反映了沼泽土壤的变化状况. 


\section{3 纳帕海湿地退化机制}

\section{1 人为活动与沼泽退化}

沼泽退化、土壤质量下降与人为活动干扰的加剧有着直接关系. 纳帕海区域内居住的少 数民族以藏族为主体, 其密度约为香格里拉其他地区的十倍. 由于人口膨胀以及传统生活方 式对木材和资源的需求, 使得沼泽周围山坡上的森林破坏严重, 除山顶和陡坡外, 目前仅为 零星残林分布, 大多演替为次生灌丛, 减弱了森林涵养沼泽水源的功能, 降雨直接以地表径 流汇入纳帕海而漏走, 而地表径流中的土壤则在纳帕海沼泽沉积, 结果造成湖面面积减少, 土壤质量变劣退化.

随着人口剧增, 当地居民在 20 世纪 70 年代初为增加农耕地, 扩大牧场, 在湖中开挖排 水沟, 扩大出水口降低水位, 致使沼泽被分割成许多部分, 成为水生生物生存的孤岛, 阻断了 生物间的交流, 破坏了生物的连续性与完整性, 更为直接的是在排水疏干的地方或开唇成耕 地或用于放牧, 直接引起沼泽逆向生态演替, 加速了沼泽退化; 低洼积水的地方又发生沼泽 化, 加剧了逆向生态演替过程. 结果导致水域大面积缩小, 湖泊萎缩, 湿地消亡. 近 20 年的 统计数字表明, 不同程度疏干沼泽土的面积约为总面积的 $90 \%$,使沼泽土壤的发育受到抑制 或停止发育,大多退化为草甸土或耕地.

纳帕海湿地遭到人为干扰后, 土壤养分明显衰减退化, 尤其是氮和有机质含量下降最为 显著. 这种人为干扰活动, 由于促进了好气细菌分解下的矿质化过程, 有机碳从沉降转换为 $\mathrm{CO}_{2}$ 释放, 土壤铵态氮和硝态氮含量呈现大幅度递增, 诱导了 $\mathrm{NO}_{\mathrm{x}}$ 气体的释放, 增加温室气 体,加重环境问题. 可见人为活动干扰对氮素营养吸收与释放以及 $\mathrm{CO}_{2}$ 沉降与释放的影响.

\section{2 旅游开发与沼泽退化}

香格里拉 人与自然和谐共生” 的世外桃源”意境, 使其成为了生态旅游热潮的一大聚 焦点 ${ }^{[19]}$. 纳帕海湿地即位于云南西北部高原远离尘世 天人合一”的香格里拉腹地. 开展生态 旅游以来, 由于没有旅游人数的控制措施, 随着游客数量增加, 游人和马匹的践踏以及粪便 和垃圾的污染 (高峰期马匹超过 1000 余匹), 加上缺乏对马队较规范的管理和无序旅游的影 响, 一方面造成水质变劣, 使得本来就破碎脆弱的浅水沼泽水体极为污浊, 而且地面水质的细 菌总数和大肠菌群两个指标, 与相邻同为自然保护区的碧塔海和属都海湿地相比高出几十至 几百倍 (未发表资料), 另一方面, 马匹和人的过度践踏巨大地破坏了沼泽土和泥炭土的草根 层, 加速了有机质分解, 促进了矿化作用, 导致沼泽土壤养分含量迅速下降而衰减退化, 严重地 区草根层被破坏殆尽,加剧了沼泽退化.

\section{3 过度放牧与沼泽退化}

随着人口增长导致的人为干扰活动加剧, 对资源需求增大而过度放牧, 可食优质牧草大 量消耗, 劣质牧草、不可食的有毒的原为伴生性的非优势种大狼毒大量增殖成为优势种, 其 花色美丽被当作旅游资源, 实际上正是草甸物种多样性组成改变、草甸退化的标志. 超出环 境容量的放牧, 不仅引起归还沼泽土的有机物质减少, 影响土壤的腐殖质积累, 打乱了沼泽 土壤生态系统正常的物质循环, 引起土壤退化, 而且造成土壤板结, 破坏地表植被和表层土 壤, 尤其是成群放养的家猪, 找食时拱翻刚排干水分的沼泽草甸的整个泥炭层, 使草根层枯 死, 泥炭土层破坏殆尽, 下覆层出露, 有机质矿化加强, 土质变劣, 养分衰竭, 破坏性巨大, 土 
壤严重退化.

\section{4 自然因素与沼泽退化}

纳帕海第三纪后期在地壳运动作用下陷落成湖, 湖盆发育在石灰岩母质的中甸高原上, 并 且一直受到喀斯特作用的强烈影响, 湖岸及湖底形成多个落水洞, 使湖水大量外泄流入金沙 江, 导致亮水区域面积减小, 湖面萎缩, 湖水深度较 20 年前普遍变浅, 虽有地下泉水和降雨等 补给, 但一年中的大部分时间水深降至 $20 \mathrm{~cm}$ 以下, 水位下降极为明显, 有的低洼地水深不足 $10 \mathrm{~cm}$, 多数仅呈过湿状态. 水位下降, 湖底暴露后成为大片浅水沼泽和沼泽草甸的纳帕海湿 地又被分割成许多部分,也加剧了逆向生态演替和退化速度.

\section{4 结论}

(1) 纳帕海沼泽湿地土壤质量下降、生态环境恶化、沼泽逆向演替退化是在自然因素的 作用下, 叠加人为干扰活动造成的. 石灰岩地质构造为纳帕海沼泽退化提供了背景, 湖水从 落水洞大量外泄为沼泽疏干退化创造了条件, 但人为活动的强列影响才是纳帕海湿地退化 的主要因素. 砍伐森林、疏干开剭沼泽、过度放牧和无序旅游等人类活动的强烈干预使得自 然因素提供的可能性成为现实.

(2)纳帕海湿地与云南西北高原上的其它湿地一样, 是在高原面上发育形成的, 由于古 夷平面受到剧烈破坏而零星分布, 因此发育的湿地之间没有水道相通, 虽然造就了丰富的生 物特有现象, 但也决定了其生态系统的脆弱性和不稳定性，一旦系统受损超过其自愈的阈限， 恢复就极为困难或不可能. 针对纳帕海湿地严重退化的现状, 应提高对其严重性的认识和重 视, 采取强有力措施修闸堵漏适度调节湖水水位, 使纳帕海湿地生态系统得到有效保护和切实 恢复.

\section{参 考 文 献}

1 殷 勇, 方念乔, 胡超涌等. 云南中甸纳帕海古环境演化的有机碳同位素记录. 湖泊科学, 2001, 14(4) 289-295

2 Raison R J, Connell M J \& Khanna P K. Methodology for studying fluxes of soil mineral-N in situ. Soil Bio Biochem, 1987, 19(5): 521-530

3 田昆, 陈宝昆, 贝荣塔等. In-situ 方法在研究退化土壤氮库时空变化中的应用. 生态学报, 2003, 23(9): 1937-1943

4 刘光崧. 土壤理化分析与剖面描述. 北京:中国标准出版社 ,1996 31-37

5 中国科学院南京土壤所. 土壤理化性质分析. 上海 :上海科技出版社, 1987 :62-93, 132-135

6 关松荫. 土壤酶及其研究法. 北京:农业出版社,1986 206-239

7 孙广友. 横断山滇西北地区沼泽成因、分布及主要类型的初步探讨. 见: 黄锡畴主编. 中国沼泽研究. 北京:科学出版社, $1988 \cdot 275-283$

8 赵魁义. 滇西北横断山区沼泽植被类型及其垂直地带性特征. 见: 黄锡畴主编. 中国沼泽研究. 北京: 科学出版社 ,1988: 284-292

9 李 恒. 横断山区的湖泊植被. 云南植物研究, 1987 9(3) 257-270

10 尹五元. 碧塔海自然保护区湿地植被研究. 西南林学院学报, 2002,22(3):16-19

11 王紫江. 云南珍稀鸟类和常见鸟类的鉴别. 昆明 :云南科技出版社, 1991:1-198

12 韩联宪. 云南鹤类越冬地及保护措施探讨. 见 : 陈宜瑜主编. 中国湿地研究. 长春: 吉林科学技术出版社,1995:256261

13 奚志农. 云南首次发现大天鹅. 云南林业 ,1992(3) 23 
14 杨 岚. 云南鹤类的分布及栖处地现状分析. 北京 :中国林业出版社, 1990:15-18

15 文贤继,杨岗, 杨晓君. 云南高原湿地水禽的分布现状. 见: 陈宜瑜主编. 中国湿地研究.长春: 吉林科学技术出版社, 1995 248-255

16 刘德隅. 云南自然保护区. 北京 :中国林业出版社,1989 269-275

17 周礼恺. 土壤酶学. 北京 科学出版社, 1987:144-166

18 李 勇. 试论土壤酶活性与土壤肥力. 土壤通报 ,1989 20(4) :190-192

19 杨桂华,齐扎拉. 滇西北香格里拉生态旅游示范区开发研究. 思想战线, 2000 26(5):82-85

\title{
The Ecological Environment Degradation and Degradation Mechanism of Napahai Karst Wetland in Southwestern Yunnan Plateau
}

\author{
TIAN Kun ${ }^{1,2}$, LU Mei $^{2}$, CHANG Fenglai ${ }^{2}$, MO Jianfeng ${ }^{2}$ \& YANG Yongxing ${ }^{3}$ \\ (1:Northeast Institute of Geography and Agricultural Ecology, Chinese Academy of Sciences, Changchun 130012, P.R.China; \\ 2: Department of Environment Science and Engineering, Southwest Forestry College, Kunming 650224, P.R.China; \\ 3: College of Environment Science and Engineering, Tongji University, Shanghai 200092, P.R.China)
}

\begin{abstract}
Based on in-situ technique of locating experiment site, a two-year study on the degradation of Napahai Karst wetland, northwestern Yunnan Plateau was carried out. The results show that there are significantly ecological environment deteriorations that are destroying the wetland. Those deteriorations include wetland shrinking, type of marsh alternation, aridity and sandification, retrogressive ecological succession, mesophytes and xerophytes instead of helophytes, biodiversity decline, soil subsidence, water quality decline and soil enzymes activities changes. The causes of natural water drainage from limestone geological structure and human interferences like over pasture, wetland reclamation and cultivation are discussed, among which the human interferences are the main driving factor that degrade the ecological environment of Napahai Karst wetland.
\end{abstract}

Keywords: Napahai Karst wetland; Southwestern Yunnan Plateau; human disturbance,;ecological environment degradation; degradation driving mechanism 